\title{
LOS CATALANES EN ESPAÑA Y LA ECONOMÍA POLÍTICA DE LA ILUSTRACIÓN: ¿ «CONQUISTA PACÍFICA» $O$ ESPAÑAS VENCIDAS?
}

\author{
JOAQUÍN OCAMPO SUÁREZ-VALDÉS \\ Universidad de Oviedo
}

Fecha de recepción: diciembre de 2010

Fecha de aceptación: febrero de 2011

\section{INTRODUCCIÓN}

Els catalans a Espanya es el título de una obra colectiva consagrada a analizar la diáspora y redes mercantiles catalanas en España. Apelar a las Españas vencidas es rendir homenaje a una de las fecundas líneas de investigación abiertas por Ernest Lluch y que aquí se explora. Conquista pacífica forma parte del título de la obra que Sidney Pollard dedicó a la triunfante expansión de la economía inglesa por el Continente ${ }^{1}$. Estas páginas estudian cómo la Economía civil del XVIII interiorizó los efectos de la integración del mercado español. En aquel siglo, la paulatina presencia de empresas y mercancías catalanas no tardó en hacerse sensible a los ojos de los viajeros y economistas ilustrados, para quienes tal hecho parecía anticipar el final de una época: la de unos mercados hasta entonces fuera de la competencia por la protección natural que les brindaban la distancia, la falta de información y los altos costes de transacción. Al amparo de tales barreras, cada región, cada comarca, había tendido a la autosuficiencia mercantil y a producir «un poco de todo».

\footnotetext{
1. Vid. PÉrez PicAzo, Ma . T., A. Segura i Mas y Ll. Ferrer i Alós (eds.): Els catalans a Espanya, 17601914, 1996, Universitat de Barcelona; E. LLUCH: «Ser extranjero sin serlo», en Las Españas vencidas del siglo XVIII. Claroscuros de la Ilustración. Barcelona, 1999, pp. 93-112, y POLLARD, S.: La conquista pacífica. La industrialización de Europa, 1760-1970, 1991, Prensas Universitarias de Zaragoza.
} 
La vertebración del mercado, pese a los beneficios agregados asociados a la ampliación de la demanda y a la especialización regional, no dejará de suscitar críticas y rechazos por las asimetrías constatadas en la distribución de aquellos beneficios. Por tal motivo, y aun cuando desde la Economía política se venía apelando a las bondades de la unidad de mercado, la percepción de las diferencias competitivas entre las regiones obligó a buscar fundamentos sobre los que legitimar la preservación de los equilibrios que sustentaban el orden económico tradicional: la «economía moral» prestará argumentos que oponer a los de un orden natural gobernado por la «mano invisible» y el «interés».

\section{CATALUNAA: LOS CAMINOS DEL MERCADO}

En 1972, Ringrose consideraba la ausencia de infraestructuras como determinante de la incapacidad de las manufacturas catalanas para encontrar mercados que no fueran los coloniales o los de las ciudades costeras peninsulares. Tiempo después, Fontana, en la estela de P. Vilar, sustentaba la opinión de que, en la España moderna, la industria solo podía surgir allí donde, previamente, «los campesinos habían aprendido a vender para comprar, donde los caminos hormigueaban con el trajín de mulas y carros transportando trigo, tejidos, aguardientes... $»^{2}$. A la explotación del mercado catalán seguirá la del español: el mercado peninsular, señala Torras, «tuvo una importancia mayor y más temprana de lo que habitualmente se supone. La integración en el ámbito arancelario de la Corona de Castilla pudo facilitar la penetración mercantil catalana, si bien subsistían exacciones, gabelas y peajes señoriales o municipales que actuaban como aduanas «en la sombra». Del mismo modo, la necesidad de metálico para hacer frente a la carga fiscal del catastro, la mejora en la redes de tráfico y en los servicios de postas, contribuyeron a facilitar la competitividad del sector comercial catalán. Esta última, a su vez, estrechamente conectada con la creación de redes y «diásporas» que reducían los costes de contratación y de acceso al crédito que operaban entre el fabricante y el «botiguer» con tienda abierta. Cuando las mercancías catalanas llegan al mercado español, este no estaba vacío: «traginers, botiguers» y «comerciants» debieron competir con las poderosas casas y compañías francesas descritas por Cabarrús, con los gremios y casas de comercio navarras o maragatas, y también con lonjistas y detallistas locales amparados por la protección natural que les brindaba la distancia ${ }^{3}$.

2. Cfr. Fontana J.: «La dinámica del mercado interior», en T. Martínez Vara (ed.): Mercado y desarrollo económico en la España contemporánea, Madrid, 1986, pp. 85-97.

3. Cfr. TorRAs, J.: «Mercados españoles y auge textil en Cataluña en el siglo XVIII», en Haciendo historia. Homenaje al profesor Carlos Seco, Universidad de Barcelona, 1989, pp. 213-218, y TORRAS, J: «La construcció del mercat», en Els espais del mercat, 1993,Valencia, pp. 11-29. 


\section{CATALUÑA COMO MODELO: «LA MÁS POBLADA, LABORIOSA, COMERCIANTE Y ACTIVA DE TODA ESPAÑA $»^{4}$}

El «arranque y destino» catalán en la España moderna era ya observable en 1720. Entre 1718 y 1787, la población del Principado ganaba medio millón de habitantes, Barcelona quintuplicaba su censo, y lo triplicaban otras muchas villas y ciudades. A la par, la agricultura conocía una creciente intensificación y sustituía cultivos de subsistencia por otros de orientación comercial. La industria rural (lana, papel, hierro, curtidos...) se extendía del Arnoia a la Garrotxa. A los capitales acumulados por el comercio levantino se sumaban los del cabotaje atlántico. La percepción y el análisis de las transformaciones de la economía catalana fueron plurales, aunque no siempre unánimes.

\section{Los viajeros de la Ilustración}

Sería prolijo enumerar a los protagonistas del tour español. En sus anotaciones sobre la economía catalana se reiteran los tópicos relativos a la laboriosidad, el avance de los cultivos, el poder de la marina y comercio... Junto a los elogios, proliferan los ejercicios, a menudo excesivamente simplificadores, de historia económica comparada: A. Jardine (1788), Bourgoing (1797) o Laborde (1809) gustan de resaltar los fuertes desequilibrios existentes entre Cataluña/Barcelona y el resto del país. Pero se trata de «paisajes» en los que en pocas ocasiones el análisis suple a la mera constatación positivista. Es el caso de A. Young (1787) cuando relacionaba la mediana propiedad con el éxito de la agricultura comercial y el aprovechamiento de los recursos hídricos. Swinburne (1779), una vez descrita la expansión del viñedo - «even upon the summits of the most rugget mountains»-, no ocultaba su admiración por los catalanes: «They are the general muleteers of Spain; you meet with them in every part of the kingdom; their honesty, steadiness, and sobriety, entitle them to confidence $»^{5}$. Joseph Townsend, tras apuntar algunos de los «méritos» catalanes -importación de maquinaria de Manchester, explotación del carbón mineral en Ripoll, innovadores hallazgos de F. Samponts y F. Salvá...-, reparaba en las ventajas del contrato enfitéutico, en la supresión de la bolla y de las alcabalas: Cataluña, «libre de la influencia paralizadora de la alcabala, dispone de una considerable superioridad sobre otras provincias» ${ }^{6}$.

De las observaciones de los viajeros españoles, retendremos tres que nos parecen del mayor interés. Antonio Ponz, en 1788, además de apelar al «carácter» catalán, es quien mejor atisba uno de los pilares del éxito de la manufacturas catalanas: «el ansia de hacer presto, ganar mucho y despachar barato», frente a los estándares habituales

4. JUNTA DE COMERÇ DE BARCELONA [1780]: Discurso sobre la agricultura, comercio e industria del Principado de Cataluña, E. Lluch (ed.), Barcelona, 1997, p. 114.

5. Cfr. Swinburne, H. [1779]: Travels Through Spain in the Years 1775 and 1776, London, Print P. Elmay, pp. 64-65.

6. Cfr. Townsend, J. [1791]: Viaje por España en la época de Carlos III (1786-1787), Madrid, 1988 p. 422. 
de la producción gremial ${ }^{7}$. Aquel mismo año, Francisco de Zamora visitaba Copons y veía en la industria rural dispersa una alternativa a la agricultura de subsistencia: «este pueblo, según su situación y terreno, sería de los más infelices de Cataluña, pero, por medio de la industria y aplicación de sus vecinos», había alcanzado un estado floreciente $^{8}$. También Beramendi, tras constatar la ventaja competitiva catalana en la industria, elogiaba las ventajas de la especialización productiva regional ${ }^{9}$.

\section{La Cataluña de los ilustrados españoles}

En el primer tercio de siglo, el mercantilismo introducirá su sesgo particular en la valoración de la performance catalana. En 1724, el ejemplo catalán le servía a Uztáriz para rechazar el tópico de la despoblación española; las reformas aduaneras de 1714 constituían a su juicio el punto de partida para la restauración demográfica, fabril y comercial. Zabala y Auñón (1732) y Bernardo de Ulloa (1740) llamarán la atención sobre las ventajas fiscales del «catastro» frente al sistema de rentas provinciales castellanas. A medida que transcurra la centuria y el despliegue catalán en el mercado español se haga notar, las consideraciones sectoriales dejan paso a visiones más integradoras o agregadas. La admiración de Nipho por el Principado le llevará a proponer una «vía catalana» de crecimiento:

«La industria y aplicación de los catalanes es uno de los mayores argumentos que se pueden hacer a las demás provincias de España para acusarles su negligencia y darles a entender que su pobreza es efecto de su omisión y no severidad de la naturaleza» ${ }^{10}$.

En Arriquibar, los «logros» catalanes se leen en clave industrialista: «El Principado de Cataluña nos presenta un modelo de conducta de cuánto puede la industria, con ser un país montuoso y distante del corazón del Reino» ${ }^{11}$. En esa misma línea, Generés advertirá que las diferencias entre la economía catalana y la de otras «provincias interiores» obedecía a una única causa:

«No es sino la grande industria que lo anima todo en Cataluña. La industria del Principado es la eficaz causa de que no haya en él un palmo de tierra que no esté cultivado; la industria es el gran móvil de su activo comercio que lo puebla y enriquece. Por ella ve el Principado esparcidos sus hijos a otras provincias» ${ }^{12}$.

7. Cfr. PonZ, Antonio: [1788-1792]: Viaje de España. Tomos XIV-XVIII. Trata de Cataluña, Aragón, La Mancha y Andalucía, Madrid, 1988, tomo XIV, p. 135.

8. Cfr. Zamora, F. de [1785-1798]: Diarios de los viajes hechos en Cataluña, R. Boixareu (ed.), Barcelona, 1973, p. 264.

9. Cfr. Beramendi y Freire, C. [1791-1796]: Viaje por España, Madrid, Biblioteca de la Fundación Lázaro Galdiano, ms., 10 vols., vol. III, fo 166-169.

10. Cfr. F. NiPHo [1770], cit. en EnCISO RECIO, L. M.: Nipho y el periodismo español del siglo XVIII, Universidad de Valladolid, 1956, p.74.

11. Cfr. Arriquibar, N. de [1779] (1987): Recreación política, J. Astigarraga y J. M. Barrenechea (eds.), Universidad de Deusto, 1987, p. 123.

12. Cfr. GENERÉS, M. D. [1793]: Reflexiones politicas y económicas sobre la población, agricultura, artes, fábricas y comercio del Reyno de Aragón, E. Lluch y A. Sánchez Hormigo (eds.), Zaragoza, 1996, p. 79. 
Citas de similar tenor se repiten en toda la literatura económica del XVIII. A finales del siglo, la recepción de Adam Smith permitía superar el viejo debate sobre la prioridad de las fuentes de riqueza, tal y como se advierte en la Introducción a un discurso sobre la economía civil (1796), de Jovellanos, y, de forma más rotunda, en Polo y Catalina:

«La industria de Cataluña, ¿ha perjudicado a los progresos de su agricultura y le ha robado los brazos necesarios, o, por el contrario, son estas las provincias de España en que se halla más floreciente, y en que no experimentan las grandes alternativas que cada día suceden en nuestras provincias interiores meramente agricultoras...? $\gg^{13}$.

\section{La Cataluña de los ilustrados catalanes}

Pierre Vilar se refería al período 1660-1705 como el de los años de «la segunda recuperación» catalana, definido por el auge demográfico, la baratura de la mano de obra rural, la acumulación de beneficios agrícolas en las masías y por la reconquista del tráfico occidental ${ }^{14}$. Exponente de ese momento de la historia económica regional será la obra de Feliu de la Penya, el Fénix de Catalunya (1683), en la que la admiración a la república comercial de Holanda va unida a la defensa del papel «civilizador» del comercio. Desde mediados de siglo, el crecimiento económico regional ya se vinculaba a su irradiación peninsular. En el Plan de la Real Conferencia de Física de Barcelona (1765) se explicaba que

«Cataluña tiene bastante acreditada su aplicación e industria (...) ¿Qué ventajas no se pueden prometer para el resto de España, tanto por la provechosa circulación con que los adelantos de una provincia excitan la aplicación de las demás, como por las muchas manufacturas y artífices con que Cataluña surte no solo el continente de España...» ${ }^{15}$.

Por las mismas fechas, Romá i Rosell expresaba con mayor énfasis los «méritos» catalanes. El crecimiento demográfico descansaba sobre la «repartición proporcionada de la propiedad». La «enfiteusis perpetua con módico precio» constituía un incentivo para la empresa agraria, pues «nunca ha sido componible con el buen cultivo el riesgo de abandonar las tierras con mucha parte de las mejoras». Los avances en la productividad proporcionaban «un sobrante de gente para los oficios» que no debería preocupar a los «idólatras» de la agricultura, porque la «deserción de los labradores hacia las artes» quedaría «superabundantemente compensado con las utilidades» de estas. El proceso se completaba con la expansión mercantil, constatable por «la multitud de artífices catalanes que se manifiesta en todas las provincias de España». El libre comercio a Indias ampliaba las expectativas: «los cosecheros de vino y los fabricantes de aguar-

13. Cfr. Polo y Catalina, J. [1804]: Informe sobre las fábricas e industria de España (1804) y otros escritos, A. Sánchez Hormigo (eds.), Zaragoza, 2005, p. 45.

14. Vid. VILAR, P.: Cataluña en la España moderna. 3. La formación del capital comercial, Barcelona, 1988, I, pp. 425-435.

15. En Nieto Galán, A. y A. Roca Rosell (coords.): La Reial Acadèmia de Ciències $i$ Arts de Barcelona als segles XVIII i XIX, Barcelona, 2000, p. 99. 
diente, están esperando la libertad de comercio a Indias para formar sus sociedades y $\operatorname{armar}$ sus saetías» ${ }^{16}$.

Capmany, en su Discurso de 1778, al interrogarse sobre las causas del despegue económico catalán, añadirá lucidez a los análisis anteriores. Comenzará apelando al hecho diferencial de aquellas regiones periféricas que, sin necesidad de la acción del gobierno y solo a partir de «sus costumbres y constitución, escupen hombres como el mar arenas ${ }^{17}$. El Discurso (1780) de la Junta de Comercio - «el text econòmic mès important dels set-cents catalá», en palabras de Lluch-, redactado cuando ya la industria se había constituido en pilar reconocible del desarrollo regional, ofrecía un balance sistemático de este último que lo hacia descansar sobre cuatro pilares. El primero, una agricultura que, «sin que podamos decir que ha llegado a la perfección», se halla «más adelantada que otras partes de España»; el segundo, el comercio, «hijo de la agricultura y de las artes», de modo que «en cualquier país donde no hubiere estos dos primeros principios, tampoco podrá verificarse que haya comercio»; en tercer lugar, y «frente a la opinión que quiere persuadir que la venta frutos es la más ventajosa a las naciones», se sostiene que la superioridad de estas «consiste en la venta de tiempo, esto es, de las producciones de la industria»; en cuarto y último lugar, en el hecho de que, a diferencia de las provincias del interior, donde «está el dinero como estancado en pocas manos», en Cataluña «es un humor que circula y se extiende por todos los miembros de su provincia» ${ }^{18}$.

\section{COMERCIO Y MERCADO EN LA ECONOMÍA POLÍTICA}

En la literatura económica española coetánea a La riqueza de las naciones, la aproximación al mercado como categoría analítica se producirá desde la perspectiva de la Economía aplicada (costes de transporte, aduanas, medios de pago, pesos y medidas...); dicho de otro modo, se hablaba más de «comercio» que de «mercado». En 1763, Nipho, a partir de máximas observables en Inglaterra y Francia, recomendaba a propietarios y colonos que, «siendo imposible que cada territorio dé todos los frutos,

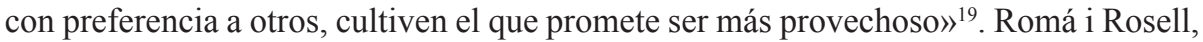
al tratar del «sistema de circulación» entre las provincias, constataba las ventajas de explotar las complementariedades regionales: «Luego que prosperan las provincias interiores, hallan en ellas las marítimas opulentas poblaciones y el pronto despacho de sus manufacturas $»^{20}$. Arriquibar, por su parte, enfatizaba el papel civilizador del comer-

16. Cfr. RomÁ i Rosell, F. [1768]: Las señales de la felicidad de España y medios de hacerlas eficaces, E. Lluch (ed.), Barcelona, 1989, p. 272, nota 1.

17. Cfr. Capmany, A. de (R. Miguel Palacio) [1778]: Discurso económico-político en defensa del trabajo, Madrid, Imp. A. de Sancha, pp. 35-37.

18. Cfr. JUNTA DE COMERÇ DE BARCELONA [1780], ob. cit., pp. 53, 83, 88, 96 y 199-202.

19. Véase F. M. NIPHO [1763]: Correo General, Histórico, Literario y Económico de la Europa, Madrid, trimestre $4^{\circ}$, p. 80

20. Cfr. RomÁ i Rosell [1768], ob. cit., pp. 115-116. 
cio: los intercambios permitirán a las provincias alcanzar la «sociedad fraternal» que surge de que «se comuniquen recíprocamente los frutos y bienes de unas a las otras» ${ }^{21}$. Generés, dado su conocimiento de la economía aragonesa, era menos optimista respecto a los efectos de la integración del mercado: las provincias marítimas, «como más fértiles, más industriosas y más comerciantes, causaron en las interiores el efecto de atraer a sí a los habitantes de las provincias más estériles»» ${ }^{22}$.

Capmany, al considerar los desequilibrios regionales centro/periferia, lo hacía en términos agregados: el estancamiento económico de Castilla se veía «compensado superabundantemente con el aumento que han recibido otras provincias, principalmente las marítimas» ${ }^{23}$. Jovellanos, en el Informe de Ley Agraria, al disertar sobre las relaciones comerciales entre provincias agrícolas e industriales, ampliaba el argumento anterior: no basta el estímulo del precio para «hacer agricultoras a unas provincias e industriosas a otras», sino que se hace preciso considerar la dotación natural y adquirida de recursos productivos:

«La naturaleza ha distribuido sus dones con diferente medida; que la agricultura y la industria suponen proporciones naturales que no pueden tener todas las provincias, y medios que no se pueden adquirir de repente; que la primera necesita extensión y fertilidad del territorio, fondos y luces, y la segunda, capitales, conocimientos, actividad, espíritu de economía y comunicaciones» ${ }^{24}$.

La difusión y asimilación de la obra de Adam Smith hará más preciso y riguroso el análisis del mercado. Será Luis Marcelino Pereira quien, tras las críticas a las concepciones mercantilistas de la balanza comercial, exprese con más brillantez las ventajas que la ampliación del mercado proporcionaba a la división del trabajo:

«Este es el bien que produce el comercio, hacer que cada país produzca aquello precisamente para lo cual es más a propósito, y que ninguna provincia se vea precisada a cultivar con desventaja suya todas las cosas necesarias a la vida o la comodidad humana ${ }^{25}$.

\section{IV. «LOS CATALANES EN ESPAÑA» DESDE LAS «ILUSTRACIONES REGIONALES»}

Se aborda ahora el tratamiento que para los ilustrados mereció la paulatina pero sostenida expansión de las mercancías catalanas en el mercado español. Una «conquista pacífica» que partiendo de la fortaleza de aquella economía regional, se vio facilitada por la integración aduanera y física del territorio; una conquista, desde luego, en

21. Cfr. ArRiQuibar [1779], ob. cit., Carta VI (1769), pp. 133-134.

22. Cfr. GENERÉS [1793], ob. cit., pp.17-18.

23. Cfr. A. de CAPMANY [1807]: Cuestiones críticas sobre varios puntos de historia económica, política y militar, J. Fontana (ed.), Diputació de Barcelona, 1988, p. 64.

24. Cfr. Jovellanos, M. G.: «Informe de Ley Agraria» [1795], en Obras completas. X. Escritos económicos, V. Llombart y J. Ocampo (eds.), Oviedo, 2008, p. 769.

25. Cfr. F. DOPICO: «El proyecto socioeconómico de los ilustrados gallegos», en E. Fuentes Quintana (dir.): Economía y economistas españoles. 3. La Ilustración, Barcelona, 2000, pp. 641-676. 
la que los catalanes no estuvieron solos, si bien fueron los principales y más visibles protagonistas.

Aragón: "pobre y despoblada por un comercio pasivo que la destruye y arruina»

Estas palabras de Arteta, escritas en 1783 para referir la postración económica aragonesa, parecían un eco de las redactadas en 1740 por Bernardo de Ulloa: «Siendo el reino de Aragón tan fructífero y barato, y abundando de lanas superfinas, ignoro la causa de que la mayor parte de ellas salgan para labrarse ${ }^{26}$. Aquella postración cuenta hoy con una dilatada trayectoria historiográfica, siendo Torras pionero en exponer el hecho de cómo Aragón, al carecer de una «trama crediticia y comercial autóctona», habría de padecer una acusada subordinación a las poderosas economías vecinas. La «diáspora» catalana en aquella región, al igual que la propia economía de Aragón, se verán espoleadas por la reordenación aduanera y la nueva planta tributaria fijadas entre 1714 y 1722, «especie de agujero negro comercial» por donde las mercancías circulaban con mayor facilidad de lo que lo hacían antes desde las fronteras francesa, navarra y vascongada. Para Cataluña, «el desmantelamiento aduanero posibilitó la aceleración de un intercambio desigual de granos, lana y aceite por textiles y otras manufacturas ${ }^{27} \gg$. Y, sin embargo, Aragón no dejará de mirarse en el espejo de la «confinante» Cataluña.

Las críticas hacia un comercio pasivo que privaba a Aragón de sus materias primas y alentaba su desindustrialización habían sido lugar común entre los arbitristas. Y así, las Noticias de Borruel (1678) y los Discursos de Dormer (1684), entre otros, se hacían eco de la creciente marginalidad y despoblación del Reino. El mismo tópico reaparecerá en la literatura económica posterior. En 1768 escribía Tomás Anzano su Discurso sobre los medios que pueden facilitar la recuperación de Aragón. Por las mismas fechas, el Canal Imperial había intensificado la salida de granos y aceites hacia los mercados extrarregionales. Entre 1768 y 1803, el 33\% del trigo español vendido en la Dieta de Barcelona era aragonés. Los circuitos comerciales eran controlados por compañías mercantiles catalanas que utilizaban los beneficios líquidos para entrar en otros mercados - arrendamiento de rentas decimales, encomiendas, crédito- por los que acceder al control de las rentas feudales. Y es que, como advirtiera P. Vilar, aunque los herederos de estos «mercaders» apostasen desde 1738 por las primeras fábricas de indianas, «los mismos hombres que, en un extremo del abanico de sus compañías se encuentran relacionados con la exacción señorial pura, participan, por el otro extremo, en la formación más moderna de capital» ${ }^{28}$.

26. Las citas, en Arteta de Monteseguro, A. [1783]: Discurso instructivo, G. Pérez Sarrión (ed.), Zaragoza, 1985, pp. 12-13, y en ULLOA, B. de [1740]: Restablecimiento de las fábricas y comercio español, G. Anes (ed.), Madrid, 1992, p. 142..

27. PÉREZ SARRIÓN, G.: «Crecimiento sin desarrollo e integración de mercados. El sector agrario aragonés en el siglo XVIII», en Estructuras agrarias y reformismo ilustrado en la España del siglo XVIII, Madrid 1989 , pp. 235-265.

28. Las citas, en P. VILAR [1988]: pp. 447-448. 
La desconfianza de Anzano hacia ese comercio hallaba su contrapunto en el optimismo expresado por Barbieri en sus Cartas politico instructivas sobre las ventajas que facilita el comercio, y proporciones del Reino de Aragón para practicarlo (1768). Por el contrario, en 1769, Nipho, con argumentos similares a los de Romá, al referirse a la tierra y partido de Alcañiz, denunciaba la especialización primario-exportadora:

«Aunque algunos (...) quieren que en los países de labranza no se establezcan manufacturas, sin duda porque no se distraigan de la labor de los campos los naturales del país agricultor, con todo, Cataluña e Inglaterra, los convence de que nada tienen las artes que perjudiquen a la agricultura.... ${ }^{29}$.

El Discurso instructivo (1783) de Arteta se redacta al calor de las expectativas alentadas por el Reglamento y arancel de libre comercio de 1778, la finalización de las obras del Canal de Aragón y de la habilitación del puerto de Los Alfaques. La Sociedad Aragonesa convocaba en 1779 un premio a la memoria que estudiase las posibilidades que en aquella coyuntura se abrían para el comercio exterior aragonés. Parecía llegar la hora de Aragón. Ese aliento late en la obra de Arteta: ya que las «las ventajas naturales son solo las verdaderas, cuya posesión no puede ser arrebatada», Aragón debería hacerse con las riendas de su destino fabril y comercial:

«Deberían nuestros comerciantes no venderlo jamás a los catalanes, sino hacer por sí mismos este tráfico [...]. No hablo de aquellos comerciantes que lejos de pensar tan honradamente quisieran que no hubiera una manufactura en Aragón [...] para poner así los precios a las ropas extranjeras $»^{30}$.

Dueños los aragoneses de las materias primas locales y controlada su comercialización, el paso siguiente será apelar a la industria transformadora. La de la seda, señalaba, «podía acarrearnos mucha riqueza si se beneficiase toda en el país» en vez de salir en rama para Cataluña. Lo mismo cabría decir del lino o de los cueros. Esta última manufactura «estaba a punto de perecer a manos de la industria catalana, que no omitía diligencia para darle el último golpe». No obstante este voluntarismo, el autor reconocía la falta en Aragón de una clase empresarial propia.

Por el contrario, el realismo de Generés partía del reconocimiento del «deplorable estado» de la economía aragonesa y de su subordinación a Cataluña para, a renglón seguido, entrar a matizar el optimismo de Arteta en dos direcciones. En primer lugar, en el relativo a las ventajas naturales: el ejemplo de Cataluña «prueba la experiencia de otros países que con su industria convierte en terrenos amenos y fértiles los incultos». Y, en segundo lugar, y dadas la falta de industria autóctona, «la distancia a Cádiz, el carecer de la aptitud para el comercio de que gozan los países marítimos, y el verse rodeada de los Reinos de Navarra, Francia, Cataluña y Valencia, más activos e industriosos», juzgaba, más recomendable que ensayar vías propias, el establecimiento de relaciones de cooperación entre ambas economías regionales: «Mas si pareciese a este

29. NIPHO, F. M [1769]: Correo General de España y noticias importantes de Agricultura, Artes, Manufacturas, Comercio, Industria y Ciencias, Madrid, Real Junta de Comercio, pp. 101-102.

30. Cfr. Arteta de Monteseguro [1783], ob. cit., pp. 30 y 79. 
Reino cosa muy ardua el fletar de un golpe naves propias (...) puede comenzar su comercio marítimo, o bien tratando con patrones, v. g. catalanes, entrando a la parte

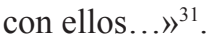

Antonio Ponz daba fe en 1788 del gran número de despoblados en una región «destituida de su comercio e industria, sumamente pobres los labradores y artesanos» ${ }^{32}$. La sangría de capitales sancionaba la tradicional orientación agraria y exportadora que glosaba Tadeo Calomarde ya a las puertas del siglo XIX. Para Ignacio de Asso, la periferización económica era un hecho secular e incuestionable. Al finalizar el siglo, formulaba un balance pesimista de la trayectoria aragonesa. El déficit comercial de la balanza aragonesa superaba los 7 millones de reales. Además de trigo, centeno, cebada, aceite, lanas, alumbre y caparrós, Aragón vendía su seda a Cataluña:

«En el día, ha aumentado tres veces la cosecha y como las fábricas, por su notable decadencia gastan muy poca, han podido los catalanes hacerse dueños de este comercio [...] Las fábricas han ido decayendo hasta el estado actual de miseria y abatimiento en que las vemos, y cual nunca experimentó aun en las épocas más calamitosas» ${ }^{33}$.

\section{IV.2. GALICIA: «LA INDUSTRIA DE ESTE PAÍS ESTA SUMERGIDA EN EL ABISMO DE LA NADA $»^{34}$}

La economía gallega del Setecientos cuenta con una dilatada historiografía en la que se analiza con detalle al contexto social y económico en el que se producirá la penetración de los «fomentadores» catalanes». La «constitución política» de Galicia, tan cara a Campomanes, comenzaba a dar claros síntomas de inestabilidad y deterioro apenas iniciado el siglo. Con 1.210.000 habitantes en 1717, la población tocaba techo en 1749 (1.350.000 almas), para estancarse a partir de entonces: el censo de Godoy (1797) registraba 1.260.000 habitantes. De las corrientes migratorias daba temprana cuenta Feijoo: «Salen muchos millares de gallegos a cavar las viñas y segar las mieses en varias provincias de España». El precario equilibrio entre población y recursos sobrevivirá, en un medio rural dominado por la amortización y el subforo, merced a estrategias de subsistencia que combinaban la explotación ganadera, la lencería doméstica, la pesca y los llamados cultivos de resistencia (maíz y patata). Y así, «en lugar de fábricas, este Reino tiene por equivalencia la industria del ganado», dirá Pedro Antonio Sánchez. Por lo mismo, la incursión catalana en sectores considerados vitales para el mantenimiento de aquel equilibrio será objeto de sonora contestación por la minoría ilustrada y por aquellos sectores sociales que vinculaban sus rentas al mantenimiento del orden económico tradicional.

31. En DÁMASO GENERÉS [1793], ob. cit., pp. 18, 46-47, 81-82, 130, 284-285, 206 y 257.

32. Vid. A. PonZ [1788]: «Trata de Aragón», en Viaje de España [1788-1792], Madrid, 1988, vol. IV tomos XV, Carta primera, p. 170, y Carta tercera, p. 217.

33. Cfr. Asso, I. de [1798] (1947): Historia de la economía politica de Aragón, J. M. Casas Torres (ed.), Zaragoza, 1947, pp. 118 y 230.

34. F. Vivero CALderón [1770], en Correo General de España [1770], núm. 17, p. 300. 
«Que solo los gallegos puedan pescar en sus mares y atajar la avaricia de los del Mediterráneo»

Con esa rotundidad expresaba fray Martín Sarmiento su oposición a la penetración de los «fomentadores» catalanes en las rías gallegas ${ }^{35}$. Aunque su presencia se remonte a las primeras décadas del Setecientos, será, en palabras de Larruga, a partir de 1750 cuando adquiera carta de naturaleza: «A mediados de este siglo, enxambres de marineros catalanes que no cabían en su país, atraídos por la fama de las marítimas riquezas de Galicia, se derramaron sobre sus costas».

La expansión, progresiva y escalonada de las artes extractivas de arrastre («xavegas») desde el Levante al Atlántico contó con variados estímulos que las empresas catalanas supieron identificar y explotar. En primer lugar, el cierre de los accesos a los caladeros noratlánticos de bacalao a raíz del tratado de Utrecht (1713) constituía una ventaja añadida para sustituir importaciones y ampliar el mercado de la sardina salada. En segundo lugar, la quiebra, desde 1730, del monopolio inglés del «peix salat». Y, en tercer lugar, la exención, fuera de su región, de que disfrutaban los catalanes de inscribirse en las «matrículas de mar», responsables del la huida de empleos y capitales autóctonos del sector pesquero. Por el lado de la demanda, se añadía el hecho de que las prescripciones religiosas convertían al pescado en elemento cotidiano de la dieta popular durante unos 140 días al año; añadidamente, en las provincias litorales con déficit cerealístico constituía un alimento complementario y de alto valor nutricional.

El giro en el mercado pesquero español fue glosado por Arriquibar: en 1769 hacía notar que «la sardina de Galicia, desde que se ha fomentado su pesca por los catalanes, ha contenido en parte la venta de bacalao». En Alicante, Townsend daba cuenta de que, si «antiguamente se importaban anualmente de Inglaterra quince cargueros de sardina», a la altura de 1786 «se las proporcionan los catalanes, quienes la pescan en las costas de Galicia». Meijide Pardo ha documentado pormenorizadamente la historia de la presencia catalana en las rías bajas y altas. Según sus estimaciones, a lo largo de la segunda mitad del siglo XVIII, podía cifrarse en 15.000 el número de catalanes desplazados estacionalmente a las pesquerías gallegas. En 1795 se documentaba que «la mayor parte del tráfico y comercio de este Reino se hace por los industriosos catalanes, que se hallan repartidos y ocupan hasta la más pequeña ensenada de la costa, sirviéndose de los naturales como precarios jornaleros para emplearlos en la pesca o comprársela en fresco». En el apogeo de su «diáspora», los «fomentadores» controlaban el $80 \%$ de las bodegas salazoneras, a la vez que extendían su ámbito de negocios y especulaciones: introducción de vinos y aguardientes como retorno a las exportaciones de sardina al Levante, comercialización de hierros vascos y géneros coloniales, arriendo de rentas decimales, aprovisionamiento y distribución de sal:

«Son infinitas las fábricas de sardina que trabajan todos los años los catalanes, cuya cosecha y fabricación en ellas comienza en agosto y dura hasta el fin de febrero.

35. Obra de los 660 pliegos (1762), cit. en F. DoPICO: A Ilustración e a sociedade galega. A visión de Galicia dos economistas ilustrados, Vigo, 1978, p. 213. 
Ejercitándose desde su emigración en este tráfico, en pocos años se hicieron ricos [...] Solo en adquisiciones que han hecho, ya disfrutan de unos dos o tres mil ducados de renta, y de un gran giro de pescados, vinos y aguardientes; y así, con su industria, han mantenido y fomentado a muchos de sus paisanos que, con bastante pobreza, han venido a su amparo y abrigo, siendo una progresión feliz de parientes del mencionado reino de Cataluña» ${ }^{36}$.

Las técnicas pesqueras y conserveras catalanas generarán un doble conflicto. En el subsector pesquero, el carácter intensivo del arrastre con «xavegas», multiplicaba y regularizaba la oferta de sardina y abarataba su precio en lonja, entrando en competencia con el sector artesanal y familiar (artes de cerco, «traiñas», «xeitos») y con los gremios de mareantes. Un gran conocedor del mundo pesquero español, Sáñez Reguart, se hacia eco de la ruptura que el arrastre suponía en cuanto a productividad: con menos barcos, las «xavegas duplican las capturas de las «traiñas». Además, añadía, «se ocupan menos brazos y el género baja a mitad de precio porque no hay tanto dispendio en jornales y rebosa abundancia». Pero el «regalado abasto» en pescados frescos hallaba su contrapartida en la disminución de brazos y de alistados en la «matrícula de mar», así como en los riesgos ecológicos derivados de la sobrepesca ${ }^{37}$. En el subsector conservero de la salazón, las prácticas del eviscerado y prensado introducían un giro radical respecto a los sistemas tradicionales. Además de subproductos comercializables (grasa de sardina), se obtenía un producto final (sardina salada o arencada) menos perecedero que las salazones gallegas y, por lo mismo, susceptible de un radio de comercialización más amplio.

Las respuestas a la presencia catalana no se harían esperar. La oposición social, en ocasiones violenta, se articuló en un amplio frente que incluirá inicialmente a pescadores y cofradías, y al que se irán sumando representantes de otros estamentos sociales (clero, hidalguía «medianera», oligarquías locales). En el caso de los pescadores, el rechazo se basaba, lógicamente, en los efectos de la ampliación de los desembarcos sobre los precios finales; además, los catalanes disfrutaban de la ventaja de quedar excluidos de las «matrículas de mar». Este último factor, junto a la pérdida del control del acceso a los recursos pesqueros y a su regulación, será el que concite la protesta de los gremios. Por su parte, el clero e hidalguía locales compartían intereses opuestos a las prácticas introducidas por los catalanes: oposición al pago de rentas decimales, control del crédito local, introducción de vinos y aguardientes que competían con las producciones locales, negativa a pagar los diezmos de mar... La contestación ideológica se expresará en un discurso heterogéneo en el que se mezclarán argumentos morales, económicos y políticos.

Una de las críticas más exacerbada a la presencia catalana es la salida de la pluma del benedictino fray Martín Sarmiento en su Obra de los 660 pliegos (1762). Los mismos argumentos de la economía moral que le servían para denunciar la penetración

36. Esta cita y la anterior, en MEIJIDE PARDO, A.: Economía maritima de la Galicia cantábrica en el siglo XVIII, Universidad de Valladolid, 1971, p. 6.

37. Cfr. SÁÑEz Reguart, A. [1791-1795]: Diccionario histórico de las artes de la pesca nacional, Madrid, 1988, II, pp. 335-344. 
del capital mercantil en la industria rural lencera se ponen ahora al servicio de la descalificación de unas relaciones económicas que amenazaban con disolver el orden y jerarquía social tradicional. Los catalanes, dirá, no solo traen a Galicia el «venenoso vino que mató a tantos millares de hombres», sino que vienen a «chupar sus frutos, sus empleos y su dinero». Por lo mismo, y desde un mercantilismo que entendía la riqueza en términos excluyentes, no dudará en reclamar su salida de las costas gallegas. Pero tal «colonialismo» económico no hubiera podido desplegarse sin la complicidad de una burguesía local que limitaba sus compromisos inversores a la búsqueda de rentas agrarias -los «señores medianeros» o subforistas-, o a actuar como meros testaferros de los «extranjeros»:

«Mientras el Rey, o algunos gallegos de cuatro costados, no piensen en establecer las fábricas [...] no hay que esperar que se establezcan, pues todos los demás son interesados en que nos las haya para llevar a Galicia las ropas de sus países, con lo cual no pocos han comenzado sus fortunas ${ }^{38}$.

En los ilustrados gallegos de la generación de Campomanes sigue echándose en falta un discurso más elaborado a la hora de analizar la novedad económica representada por la presencia catalana. En su crítica a la presencia catalana, más que de antiindustrialismo cabe hablar de la frustración por la inexistencia de fuerzas sociales autóctonas capaces de explotar los recursos locales, lo que explica que se sigan empleando los argumentos morales:

"Vivía este país en el seno de la paz y de la abundancia, y he aquí que se presentan los industriosos catalanes, esos holandeses del mediodía, esos hombres especuladores cuyas operaciones dirige solo el interés [...]. Transforman el comercio de los naturales dejándolos en situación precaria, empeñándolos en contratos que causan ruina, y anticipándoles en vinos y aguardientes el valor de su futuro trabajo, vician sus costumbres y fomentan su ociosidad $»^{39}$.

En 1775, Somoza de Monsoriú glosaba en términos similares los efectos de un mercado que ponía en contacto a economías con dispares niveles de desarrollo:

«La pesca de los catalanes en Galicia, y la franqueza y métodos con que la ejecutan, es otro estorbo considerable a la riqueza de la nación [...]. Nunca pensaron los marineros gallegos en desterrar de su país a los catalanes. Los gallegos impugnan solo la existencia volante en sus países de unos hombres que solo duran en sus puertos y rías interim no se enriquecen con sus frutos [...]. Los catalanes no necesitan la pesca de Galicia para ser felices y poderosos $»^{40}$.

En los ilustrados finiseculares, la familiaridad con el instrumental analítico proporcionado por la Economía política ayudará a precisar los diagnósticos sobre la

38. Cit. en F. DOPICO, ob. cit., p. 113.

39. En CORNIDE y SAAVEDRA, J. A. [1774]: Memorias sobre la pesca de la sardina en las costas de Galicia, Madrid, Imp. de J. Ibarra, pp. 59-60.

40. En SOMOZA De Monsoriú [1775]: Estorbos y remedios de la riqueza de Galicia. Discurso político legal, Barreiro Fernández (ed.), Santiago de Compostela, 1995, pp. 126-131. 
economía regional: en esa misma medida, los argumentos morales o normativos irán cediendo ante los positivos. Y así, en Lucas Labrada, el «atraso» deja ya de vincularse a factores exógenos. En 1804, cuando ya iban «haciéndose cada vez más familiares los principios de la Economía civil», justificaba el nuevo orden económico por el hecho de que «las relaciones mercantiles se han multiplicado y han sido los puertos un punto de atracción para el comercio». En esa dirección, añadía, resultaba lógico que «una clase de vasallos que se hallaba sumergida en la miseria, sin crédito para hacer las anticipaciones», se limitase a pescar «por cuenta de armadores que, anticipadamente, les compraban los frutos de su industria». Aun cuando defendía la libertad de pesca y se oponía a la «matrícula de mar» porque convertía la pesca en un privilegio solo al alcance de los matriculados, en tanto se mantuviese aquella, añadía, «los privilegios solo animan a aquellos que son capaces de aprovecharse de ellos ${ }^{41} \gg$.

En ese mismo contexto doctrinal, Pedro Antonio Sánchez, reconociendo que los pueblos del litoral, desde Coruña a Bayona, se hallaban «notablemente arruinados»y que la economía gallega «veía desde sus casas caminar para el bolsillo de los extraños lo que debiera ser mayorazgo de sus familias», no dejaba de reclamar las ventajas de la libertad de pesca ${ }^{42}$. Pero será Luis Marcelino Pereira quien, consecuente con los principios de la nueva economía, asuma las ventajas del libre acceso a los recursos marinos. Pese a todo, el discurso político seguirá manteniendo vivos los recelos hacia la presencia catalana:

«Adviértase que la palabra «catalanes» no debe entenderse como suena, de otro modo sería una ofensa que oscurecería el esplendor de una región generosa y acreedora de una estima muy elevada [...]; aquí se llama «catalanes» a cierto número de hombres que, de la noche a la mañana, aparecen avecindados a las orillas de nuestros mares [...] enemigos declarados de la sociedad» ${ }^{43}$.

\section{IV.3. DE LAS COSTAS CANTÁBRICAS A LAS ANDALUZAS, DE CASTILLA A EXTREMADURA}

\section{«Podríamos competir con los catalanes»}

Así lo expresaba Jovellanos en un Discurso sobre los medios de promover la felicidad del Principado (1781), en que pormenorizaba sobre la presencia comercial catalana en Asturias y en las costas cantábricas: con su «buena industria y comercio», desde sus bases pesqueras en Huelva y Ayamonte, se habían hecho con todo el mercado de «sardina arenque» de las costas cantábricas. En el Informe de ley agraria, las

41. Cfr. L. LABRADA, L. [1804]: «Observaciones generales sobre la población, agricultura...», en Descripción económica del Reino de Galicia, F. Rio Barja (ed.). Vigo, Galaxia, pp. 250 y 254-255.

42. SÁNCHEZ, Pedro Antonio [1806]: «Memoria sobre los abastos y policía» y «Representación sobre navegación del Miño», en La economía gallega en los escritos de Pedro Antonio Sánchez, X. M. Beiras (ed.). Vigo, 1973, pp. 197-198, y nota 10.

43. «Carta muradana» (1813), cit. en Alonso ÁlvareZ, L.: Industrialización y conflictos sociales en la Galicia del Antiguo Régimen, Madrid, 1976, pp. 94-95. 
mismas conclusiones se extendían a los vinos: pese a la proximidad y calidad de los de Rueda, Nava y La Seca, «todavía se despachan mejor los de Cataluña, que alguna vez arriban a sus puertos, y no sería mucho que con el tiempo, desterrasen del todo a los vinos castellanos $\left.{ }^{44}\right\rangle$. Arriquibar había llegado a una conclusión similar unos años antes: «Se ha visto que la sardina de Galicia, desde que se ha fomentado su pesca por los catalanes, ha contenido en parte la venta de bacalao, por lo menos en Bilbao, por lo mucho que la gente pobre se tira a ella en Cuaresma ${ }^{45}$.

Además de aquella presencia marítima, el eje comercial San Sebastián-BurgosZaragoza-Barcelona constituía un corredor que aprovechaban las casas de comercio catalanas para sus tratos y giro con la Compañía Guipuzcoana de Caracas. En 1763, un corresponsal de Nipho para la Estafeta de Londres daba noticia de la presencia de navíos catalanes de elevado porte que llevaban sardina arencada a los puertos del norte, cargando en retorno hierro vasco. Para la Real Sociedad Cantábrica también los «catalanes industriosos han mostrado la senda y el giro» que deben guiar tanto el comercio como la pesca. Caamaño y Pardo, en 1797, destacaba cómo aquellos, una vez adquirido el pescado a los naturales, «saben volverse a su primer dinero con ofrecer al pescador cuantos géneros necesita para mantenerse y vestir». No obstante, como ocurriera en Galicia, no faltarán las críticas hacia la competencia foránea, tanto a la procedente de las «provincias exentas» como hacia aquellos otros «mercaderes extranjeros que no tienen patria ni miran sino al interés del momento y a su privativo e individual beneficio» ${ }^{46}$.

De Castilla a Extremadura: «apenas hay pueblo de consideración en que no se haya establecido algún catalán» ${ }^{47}$

Las recientes investigaciones sobre pautas de consumo y comercialización han ido acumulando evidencias que corroboran el aserto de Larruga que encabeza esta sección. En 1779, cuando Campomanes recorría Jadraque anotaba que la mayor parte de la cosecha de rubia se extraía para Cataluña, y añadía que existía «un comercio regular entre castellanos y catalanes». La adquisición de materias primas y su presencia en ferias y mercados de las principales villas y capitales de provincia abrieron la puerta a las manufacturas catalanas. En Salamanca, el comercio de tejidos de la capital estaba en manos de las casas de comercio «Puyol e Hijos» y «Coll y Colomer», entre otras ${ }^{48}$. En Madrid, los tejidos de lana de Tarrasa, Sabadell e Igualada competían con los elaborados por las Reales Fábricas de Ezcaray, Guadalajara o Brihuega,

44. JovelLanos [1795]: «Informe de Ley Agraria...», ob. cit., p. 808.

45. Cfr. ARRIQUiBAR [1779], ob. cit., Carta VII (1763), p. 169.

46. Cfr. Demerson, P. de: Próspera y adversa fortuna de la Real Sociedad Cantábrica (1775-1804), Santander, 1986, pp. 117-120.

47. En LaRruga, E. [1787-1800]: Memorias políticas y económicas sobre los frutos, comercio, fábricas y minas de España, Zaragoza, 1995, VII, pp. 168-169.

48. Cfr. Ros Massana, R.: La industria textil lanera de Béjar (1680-1850). La formación de un enclave industrial, Junta de Castilla y León, 1999, p. 223. 
tal y como Larruga advirtiera en 1788 al referirse a las ventas del gremio de roperos madrileños: «Es mucho mayor el consumo que hace [Madrid] de varios géneros de las fábricas de Cataluña, pues es muy notorio que emplean muchas partidas de cotones pintados de las fábricas de Tarrasa, Sabadell, Igualada, y otras». Y haciéndose eco de las diásporas catalanas, añadía:

«Los que aman la pereza [...] y los que quieren hacerse ricos con poco trabajo [...] no se avienen bien con los establecimientos que hacen los catalanes fuera de su Principado; pero las gentes sensatas piensan de muy distinto modo, pues aprecian a estos hombres a quienes miran como hermanos y buenos españoles ${ }^{49}$.

El mismo modelo se repetirá en Extremadura, región que servía de puente entre los puertos catalanes y las ferias y villas castellanas. Al comercio de tejidos se sumaba la adquisición de materias primas y, en una etapa posterior, la inversión inmobiliaria y crediticia.

\section{Del Levante al Atlántico, pasando por Andalucía}

Los puertos levantinos, además de sus funciones de intermediación en el cabotaje comercial mediterráneo y en el comercio colonial, fueron visitados por las compañías catalanas por las potencialidades que ofrecían para áreas específicas de negocio. En el caso de Murcia, además de la seda y la barrilla, aquellas casas de comercio encontraron la oportunidad de aprovechar las múltiples demandas suscitadas por el arsenal de Cartagena. En Valencia, señalaba Nipho, los catalanes introducían «harinas, trigo y vino»; en tanto, Cavanilles se quejaba de que en Valencia «se ven muchos con sombreros y gorros catalanes, alterando así el vestido nacional» ${ }^{50}$.

En Alicante, «llondros» y «saetías» de la misma procedencia dominaban el tráfico mercantil marítimo y, desde el último tercio del siglo, tras el ocaso del monopolio británico en el comercio del arenque y bacalao, habían convertido aquel puerto en la vía de penetración de las salazones de pescado en Castilla. Así lo había advertido Joseph Townsend: «En Alicante entran entre quinientos y mil barcos al año, la mayoría de los cuales son catalanes (...). Aunque antiguamente Alicante importaba anualmente de Inglaterra quince cargueros de sardina, ahora se las proporcionan los catalanes, quienes la pescan en las costas gallegas $\rangle^{51}$.

Del absentismo empresarial andaluz y de su incapacidad para abastecer el mercado regional se ha dicho que debería atribuirse más a la falta de iniciativas inversoras que a la carencia de capitales. La historiografía económica ha tratado ampliamente tanto la no industrialización andaluza como las relaciones comerciales entre Cataluña y Andalucía. Martínez Shaw subraya la paradoja que ofrece el análisis comparado: si

49. E. LARRUGA [1792], ob. cit., VII, pp. 168-169.

50. Cfr. F. M. NiPHO [1769]: Correo General de España, ob. cit., p. 248; A. de CAPMANY [1778], ob. cit., p. 41, y CAVANILLES, A. J. [1795-1797]: Observaciones sobre la historia natural, geografía, agricultura, población y frutos del Reino de Valencia, J. M. Casas Torres (ed.), Zaragoza, 1958, p. 198.

51. Cfr. J. TOWNSEND [1791]: ob. cit., pp. 369 y 372. 
en Cataluña la expansión productiva (agrícola y manufacturera) sentó las bases de la expansión marítima y mercantil, en la Baja Andalucía el predominio de las actividades terciarias (crédito, comercio) marchó unido a la decadencia de los sectores básicos, sometidos a la competencia exterior ${ }^{52}$.

Pesca, salazones, fletamentos navales, asientos con los arsenales, manufacturas textiles y de curtidos, y comercio de aceites, vinos y coloniales, fueron algunos de los ramos de negocio que atrajeron el interés empresarial de las colonias catalanas asentadas en Andalucía. No había puerto ni camino, feria ni ciudad que no conociese la presencia de mercaderes, trajineros o factores catalanes. Una presencia que podía remontarse a los primeros años del siglo, cuando ya los cosecheros jerezanos pugnaban frente a los cargadores de Cádiz por excluir los caldos, aguardientes y frutos secos catalanes del «tercio de frutos» de la flota de Indias. Sabemos por Townsend de su hegemonía en el cabotaje mercantil levantino. Delgado Ribas lo confirma al dar cuenta de cómo los «llondros»y «llauds» de Canet, Mataró y Tortosa dominaban los circuitos mercantiles levantinos. En el caso de Málaga, la rivalidad entre los patrones locales y catalanes aparece referida en el Informe sobre fomento de la marina mercante (1784), dirigido por Jovellanos a la Junta de Comercio. También debían de ser catalanas muchas de las compañías mercantiles dedicadas al comercio de aceite citadas por Francisco Bruna en uno de los expediente del Informe de Ley Agraria, y por Jovellanos en uno de sus informes sevillanos sobre extracción de aceites a reinos extranjeros. Los testimonios de viajeros abundan en los hechos comentados. Nipho, hablando de Antequera, anotaba: «Continuamente circulan por esta ciudad los catalanes, que sin fijar puestos públicos para la distribución y venta de sus géneros, venden encajes, blondas, abanicos, medias y pañuelos, con que extraen mucho dinero, pues apenas hay día del año en que no hay por las calles carros $\rangle^{53}$.

Un miembro de la Sociedad de Verdaderos Patricios de Baeza escribía en 1774:

«Las estameñas, la sarga, el anacoste, el cotón, las indianas o pintados de algodón, todos estos son géneros ordinarios con que se viste la gente pobre, y ninguno de ellos se hila ni teje ni fabrica en Jaén (...). Para Jaén, lo mismo es que estas y otras telas vengan de Francia o de Cataluña. De cualquier parte que vengan, se llevan el dinero que nunca ha de volver a nosotros $»^{54}$.

En el sector pesquero, aun cuando la presencia de armadores catalanes en las costas de Málaga se remonte al siglo XVI, la expansión del arrastre con parejas (bous) en las costas andaluzas se comienza a documentar a partir de la segunda década del siglo,

52. Cfr. Martínez SHAW, C.: «Las relaciones económicas entre Cataluña y la Baja Andalucía en el siglo XVIII. Un intento de interpretación», en Andalucía Moderna (siglo XVIII) (I Congreso de Historia de Andalucía: Actas), Córdoba, 1978, I, pp. 127-139.

53. Cit. en Muset i Pons, A.: «Ferias y mercados al servicio del negocio catalán (siglo XVIII), en J. Torras y B. Yun: (eds.), Consumo, condiciones de vida y comercialización. Cataluña y Castilla en los siglos XVII-XX, Valladolid, 1999, p. 326.

54. Cit. en Arias de SaAvedra, I. (1987): Las Sociedades Económicas de Amigos del País del Reino de Jaén, Universidad de Granada, 1987, p. 43. 
generalizándose desde 1740. Las colonias más numerosas se emplazaban en Huelva, donde, hacia 1720,

«comenzaron a venir a Ayamonte algunos buques catalanes de cabotaje por los meses de julio y agosto que varaban su barcos, y con sus lanchas y tripulaciones y un boliche o pequeña red de saco, salían a la costa de Las Cabezas, cogían algunos millares de sardinas que salaban en pequeños almacenes en la punta de La Gandera, y después de la chancra conveniente, las estibaban y prensaban, y regresaban a Cataluña (...) y volvían al año siguiente» ${ }^{55}$.

En 1755, aquella explotación estacional de las pesquerías había dado paso a la formación en Isla Higuerita de una colonia y factoría estable de unos 1.500 «forasteros» en la que operaban más de una treintena de compañías catalanas -A. Salerich, B. Coll, A. Rivera, J. Pascual...-, cuyo volumen de negocio superaba «los 300.000 pesos corrientes de plata y oro». Una real orden de 1755 eximía a las mismas del pago de derechos de millones por el aguardiente, vino, aceite, vinagre, madera y otras materias primas. Veinte años después, en 1775, en la matrícula naval de aquel enclave se registraban 57 embarcaciones, 733 pescadores y 507 salazoneros catalanes. En Ayamonte y Montegordo (Portugal) se asentaron otras colonias pesqueras del mismo origen.

Sáñez Reguart, que a finales del siglo corroboraba el dominio pesquero y salazonero catalán en las costas de Alicante y Cádiz, denunciaba con criterios conservacionistas el carácter esquilmante del arrastre con parejas porque «arranca las hierbas, no permite a ningún pez que escape» y se «exerce todo el año, en todo tiempo y a todas alturas». También acudía Sáñez a criterios sociales para desaconsejar aquellas artes: el arrastre eliminaba brazos y, por lo mismo, acarreaba la crisis de las pesquerías tradicionales, poniendo en cuestión la subsistencia de las villas marineras y la disponibilidad de brazos para las matrículas de la Armada. Para ilustrarlo, ponía un ejemplo llamativo de las diferencias de productividad entre las nuevas artes de propulsión a la vela («bous» o parejas de arrastre) y las tradicionales: 4 parejas ( 80 tripulantes) capturaban en 8 horas el equivalente a lo desembarcado por 40 lanchas palangreras (200 pescadores) en 24 horas, y ello «sin tener que remar ni sufrir gastos de carnada» ${ }^{56}$.

La Sociedad Patriótica de Sevilla publicaba en 1779 la Memoria sobre la decadencia de la pesca en las costas de Andalucía, de Martínez de Mora, en el que, en relación al arrastre con bous, podía leerse:

«Es opuesto al fomento de las marinería e industria [...] de forma que recibiendo este arte más capitales y menos barcos y menos brazos, entre cuatro ricos arman unas barcas, cogen más pescado que diez veces más gente con otras artes [...] y esto desalienta a los marineros y los arruina, y sufren quebranto todos los oficios que trabajan en los diferentes ramos de la industria marítima, como construcción de buques, redes, cordelería...».

55. Cfr. Miravent, J. [1824]: Memoria sobre la población y progresos de la Real Ysla de La Higuerita, Huelva, 2006, p. 142.

56. Cfr. SÁÑEZ REGUART [1791-1795]: ob. cit., I, 320-382. 


\section{CONCLUSIONES: ¿«ESPAÑAS VENCIDAS» O CONQUISTA PACÍFICA?}

En los estudios sobre el proceso de formación del mercado peninsular se sostiene que la actuación combinada de los impulsos económicos e institucionales tendieron a reducir los «obstáculos físicos» y los «estorbos políticos» que dificultaban su integración. En la misma medida en que se reducían los costes de transacción progresaba la eficiencia en la asignación de factores y recursos, así como la especialización regional. Pero no siempre la agenda de los hechos económicos determinó la del análisis de los «economistas». Los argumentos esgrimidos por quienes, como Sarmiento, condenaban como «especuladores» a los catalanes han de ser entendidos más en términos políticos que morales. Siendo cierto que expresaban el temor a la disolución del orden social y económico tradicional, no lo era menos que referían igualmente el temor a los efectos de la competencia entre economías con niveles de desarrollo diferenciados: esquilmo de recursos, proletarización, control del crédito y del comercio, drenaje de capitales... En tal sentido, calificar como «anticapitalistas» $\mathrm{o}$ «antiindustrialistas» tales posiciones no ayuda a comprender mejor la realidad que pretendían denunciar.

Quienes, desde el ámbito teórico de la Economía civil, no dudaron en defender los supuestos del «interés propio», del «orden natural» y del mercado como equilibradores espontáneos de la economía no tardaron en percibir los efectos no deseados derivados de la «mano invisible». La lectura de la balanza comercial en términos excluyentes dará paso progresivamente a la aceptación de la lógica del mercado y de su inevitabilidad. Esta última era expuesta de forma concluyente en 1830 por la Diputación de Comercio de Extremadura:

«La Diputación no desconoce que sería un absurdo pensar que todas las provincias floreciesen de igual modo en el Reino; está persuadida que cada una debe abrazar aquellos ramos de industria que más se acomoden a las producciones de su territorio, y que si Cataluña excede a Extremadura en fábricas y productos industriales, debe esta llevar una ventaja considerable a aquella en la agricultura; está convencida también de que si los habitantes de Cataluña se trasladaran a Extremadura, se convertirían bien pronto en labradores; al paso que los extremeños en Cataluña serían a su vez artistas industriosos ${ }^{57}$ ».

Así y todo, una cosa era el discurso económico y otra bien distinta el discurso moral y político. La economía catalana «conquistó pacíficamente» el mercado español sin que ello evitara que, desde las regiones periféricas y/o «provincias interiores», tal hecho se interiorizase en términos de «derrota». Abusando del símil bélico, puede afirmarse que los economistas que escribían sobre el tema sabían -y no dudaron en denunciarlo- que «el enemigo estaba dentro»: eran la debilidades internas de cada economía las que abrían las puertas a aquella «conquista». Pero tal consideración en nada empañaba el sentimiento de «derrota» económica: es en este exclusivo sentido desde el que cabe hablar, recordando a Lluch, de «otras Españas vencidas».

57. Cit. en Moreno FERnÁndez, J. R. (2004): «La articulación y desarticulación de regiones económicas en la España de la revolución liberal», en E. Llopis (ed.), El legado económico del Antiguo Régimen en España, Barcelona, 2004, pp. 229-272. 